\section{Commentary: The moderately dilated ascending aorta: To wrap or not to wrap?}

\author{
Nicholas R. Hess, MD, ${ }^{a}$ and Danny Chu, MD ${ }^{\mathrm{a}, \mathrm{b}}$
}

In this issue of the Journal, Kim and colleagues ${ }^{1}$ present a comparison of 2 techniques for managing a moderately dilated ascending aorta-ascending aortic replacement (AAR) or ascending aortic wrapping (AAW) - at the time of aortic valve replacement. Perioperative morbidity and late survival were similar; however, AAW was found to be associated with late proximal arch dilation. Annulus, sinus, and ascending aorta measurements did not progress in either cohort.

In today's practice, AAW has been largely replaced by AAR and is reserved for the elderly, medically complex, and/or more frail patient populations. ${ }^{2}$ As demonstrated by Kim and colleagues, AAW requires shorter cardiopulmonary bypass and cross-clamp times, while obviating the need for hypothermic circulatory arrest. A strength of this study is the long-term follow-up (median, 7.1 years; interquartile range, 3.9-11.2 years), which has seldomly been reported in previous studies. Annual proximal arch growth was approximately $0.34 \mathrm{~mm} /$ year after AAW. The mechanism of redilation remains to be elucidated, but this may be related in part to aortic wall atrophy, and loss of distinct vessel layers may occur in the reinforced aortic segments after AAW. ${ }^{3,4}$ Should this process extend beyond the limits of

From the a Division of Cardiac Surgery, Department of Cardiothoracic Surgery, University of Pittsburgh School of Medicine and ${ }^{b}$ University of Pittsburgh Medical Center Heart and Vascular Institute, Pittsburgh, Pa.

Disclosures: Dr Chu is a current proctor/consultant for Japanese Organization for Medical Device Development, has served on the faculty of The Osler Institute, and has served as a journal editor for Wolters Kluwer Health. Dr Hess reported no conflicts of interest.

The Journal policy requires editors and reviewers to disclose conflicts of interest and to decline handling or reviewing manuscripts for which they may have a conflict of interest. The editors and reviewers of this article have no conflicts of interest.

Received for publication March 23, 2021; revisions received March 23, 2021; accepted for publication March 24, 2021; available ahead of print March 30, 2021.

Address for reprints: Danny Chu, MD, Division of Cardiac Surgery, Department of Cardiothoracic Surgery, University of Pittsburgh School of Medicine, 200 Lothrop St, Suite C-711, Pittsburgh, PA 15213 (E-mail: chud@upmc.edu).

J Thorac Cardiovasc Surg 2022;164:475-6

$0022-5223 / \$ 36.00$

Copyright (C) 2021 by The American Association for Thoracic Surgery

https://doi.org/10.1016/j.jtcvs.2021.03.088

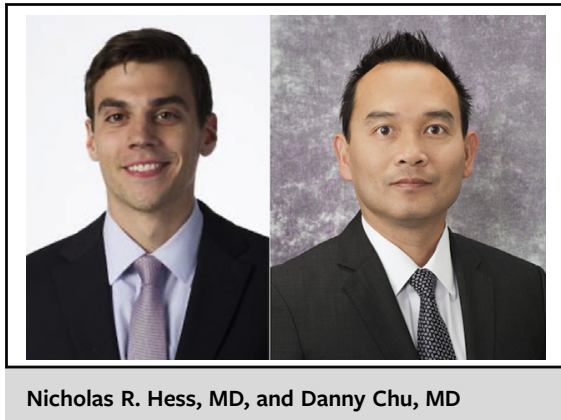

CENTRAL MESSAGE

At the time of aortic valve replacement with moderate ascending dilation, aortic wrapping was associated with similar morbidity and survival to replacement, but with late proximal arch dilation.

the reinforcing graft material, the perigraft region of weakened aorta may be prone to dilation, which may encourage graft migration and further exposure of atrophic aorta. Nonetheless, this process appears to a be rather insidious one.

Although this study provides great insight into the longterm outcomes following these procedures, there are some weaknesses worth mentioning. As admitted by the authors, the technique of AAW is generally reserved for the older and frail patient population base. As such, it is likely that propensity score matching, although a useful tool, might not be able to account for this degree of selection bias. As a result, the conclusions of this study must be contextualized in light of this potential bias. Although perioperative outcomes and long-term survival were similar in the 2 treatment arms, it might not be reasonable to conclude that AAW is a comparable alternative to AAR for all patients.

In conclusion, Kim and colleagues provide a valuable resource in reporting their long-term outcomes of moderately dilated aorta management during aortic valve replacement in a propensity score-matched fashion. Perioperative outcomes and long-term survival were similar between cohorts, but AAW was associated with higher rates of proximal arch redilation and long-term adverse aortic events (significant redilation and/or reoperation). Although propensity matching might not be able to 
control for all confounding differences between study cohorts, their findings suggest that AAW may be an ideal choice for the elderly patient population or those with a reduced life expectancy, especially those in whom prolonged cardiopulmonary bypass times and/or hypothermic arrest might not be tolerated. Because proximal arch redilation may occur, yearly rates appear to be insidious, and periodic postoperative surveillance may be warranted.

\section{References}

1. Kim H-H, Lee S, Lee SH, Youn Y-N, Yoo K-J, Joo H-C. The long-term fate of ascending aorta aneurysm after wrapping versus replacement. J Thorac Cardiovasc Surg. 2022;164:463-74.e4.

2. Gonzalez-Santos JM, Arnaiz-Garcia ME. Wrapping of the ascending aorta revisited: is there any role left for conservative treatment of ascending aortic aneurysm? J Thorac Dis. 2017;9(Suppl 6):S488-97.

3. Neri E, Massetti M, Tanganelli P, Capannini G, Carone E, Tripodi A, et al. Is it only a mechanical matter? Histologic modifications of the aorta underlying external banding. J Thorac Cardiovasc Surg. 1999;118:1116-8.

4. Doyle M, Peeceeyan S, Bonar F, Horton M. Rarefaction of the aorta under Dacron wrap: a rare complication. Interact Cardiovasc Thorac Surg. 2014;19:341-3.

\section{See Article page 463.}

\section{Commentary: Wrap one's aorta around}

\author{
Vicente Orozco-Sevilla, MD, ${ }^{\mathrm{a}, \mathrm{b}, \mathrm{c}}$ and \\ Tomas A. Salerno, MD $^{\mathrm{d}}$
}

Wrapping techniques, with or without aortoplasty, ${ }^{1-3}$ have been used as a less-invasive surgical alternative for the treatment of moderately dilated aortas during other cardiac surgery procedures (ie, those that are not primarily focused on aortic repair). Additionally, there are subsets of patients with aortic disease, such as those with advanced age or those with multiple comorbidities, that face a greatly enhanced risk of operative death during proximal aortic repairs (eg, of the ascending aorta and transverse arch) that center on aortic replacement. ${ }^{4}$ Aside from the aortic wrapping technique's technical simplicity, enthusiasm for its use is low due to the lack of long-term results, especially in comparison to alternate approaches

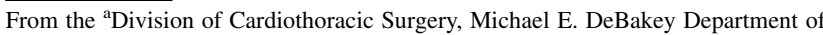
Surgery, Baylor College of Medicine, Houston, Tex; ${ }^{\mathrm{b}}$ Section of Adult Cardiac Surgery, Department of Cardiovascular Surgery, Texas Heart Institute; Houston, Tex;

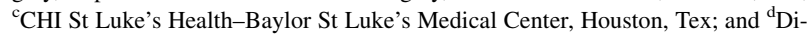
vision of Cardiothoracic Surgery, Miller School of Medicine, University of Miami and Jackson Memorial Hospital, Miami, Fla.

Disclosures: The authors reported no conflicts of interest.

The Journal policy requires editors and reviewers to disclose conflicts of interest and to decline handling or reviewing manuscripts for which they may have a conflict of interest. The editors and reviewers of this article have no conflicts of interest.

Received for publication March 29, 2021; revisions received March 29, 2021; accepted for publication March 29, 2021; available ahead of print April 2, 2021.

Address for reprints: Tomas A. Salerno, MD, Division of Cardiothoracic Surgery, Miller School of Medicine, University of Miami, 1611 NW 12th Ave, Miami, FL 33136 (E-mail: tsalerno@med.miami.edu).

J Thorac Cardiovasc Surg 2022;164:476-7

$0022-5223 / \$ 36.00$

Copyright (c) 2021 by The American Association for Thoracic Surgery

https://doi.org/10.1016/j.jtcvs.2021.03.099

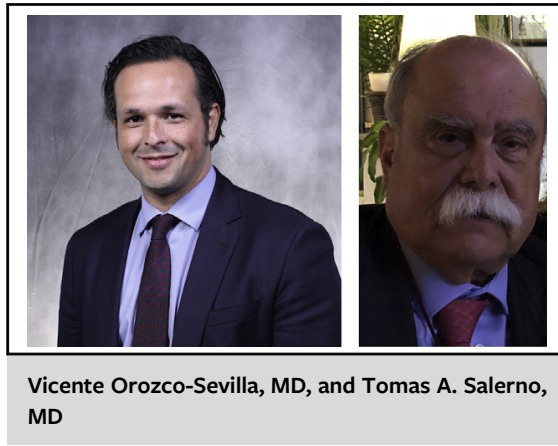

CENTRAL MESSAGE

Aortic wrapping should be in the armamentarium of every surgeon to selectively reinforce the aorta. such as aorta replacement. Presumed complications of aortic wrapping include migration, erosion, ulceration, and atrophy of the aortic wall caused by possible biomechanical, structural, and histologic changes associated with the wrapping. ${ }^{5}$

Kim and colleagues ${ }^{6}$ provide us with an update of their experience with the management and long-term prognosis of 4 other aortic regions (ie, annulus, sinus, ascending aorta, and proximal arch) when a moderately dilated ascending aorta during aortic valve surgery was wrapped or replaced. The authors reviewed 964 patients undergoing aortic valve surgery between 1995 and 2018; they excluded patients with congenital anomalies or aortic dissections and patients who had concomitant aortic root or aortic arch surgery or concomitant mitral valve or 